ARTICLE

DOI: 10.1038/s41467-018-02909-6 OPEN

\title{
Nanobody-triggered lockdown of VSRs reveals ligand reloading in the Golgi
}

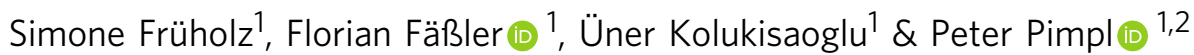

Protein degradation in lytic compartments is crucial for eukaryotic cells. At the heart of this process, vacuolar sorting receptors (VSRs) bind soluble hydrolases in the secretory pathway and release them into the vacuolar route. Sorting efficiency is suggested to result from receptor recycling. However, how and to where plant VSRs recycle remains controversial. Here we present a nanobody-epitope interaction-based protein labeling and tracking approach to dissect their anterograde and retrograde transport routes in vivo. We simultaneously employ two different nanobody-epitope pairs: one for the location-specific posttranslational fluorescence labeling of receptors and the other pair to trigger their compartment-specific lockdown via an endocytosed dual-epitope linker protein. We demonstrate $V S R$ recycling from the TGN/EE, thereby identifying the cis-Golgi as the recycling target and show that recycled VSRs reload ligands. This is evidence that bidirectional VSR-mediated sorting of vacuolar proteins exists and occurs between the Golgi and the TGN/EE.

\footnotetext{
${ }^{1}$ Center for Plant Molecular Biology (ZMBP), University of Tübingen, Auf der Morgenstelle 32, 72076 Tübingen, Germany. ${ }^{2}$ SUSTech-PKU Institute of Plant and Food Science (IPFS), Department of Biology, Southern University of Science and Technology (SUSTech), 1088 Xueyuan Rd, Shenzhen 518055, China. Correspondence and requests for materials should be addressed to P.P. (email: pimpl@sustc.edu.cn)
} 
$\mathrm{D}$ egradation in lytic compartments is a hallmark of eukaryotic cells. It allows for rapid modulations of compartmental protein and lipid compositions as responses to cellular communication or environmental cues ${ }^{1-4}$. This necessitates constant supply of vacuoles/lysosomes with acid hydrolysis by the action of sorting receptors ${ }^{5}$. Despite its significance for viability and development, the core mechanism of vacuolar sorting receptor (VSR)-mediated protein transport and its implementation in the plant endomembrane system is still controversial ${ }^{5,6}$.

The concept of receptor-mediated protein transport dates back to the discovery of the low-density lipoprotein receptor and the cation independent (CI)-mannose 6-phosphate receptor (MPR) for lysosomal sorting in mammals ${ }^{7-9}$. They bind ligands either at the cell surface or the TGN and transport them to endosomes, where ligands are released due to low compartmental $\mathrm{pH}^{8,10}$. The key to the efficiency of this transport however, is the continuous recycling of receptors after ligand release, allowing receptors to go through hundreds of transport-cycles during their lifespan ${ }^{7,8,11-13}$.

The recycling route of MPRs was most elegantly mapped biochemically, by assaying for Golgi cisternae-specific glycan processing after receptor labeling with $\left[{ }^{3} \mathrm{H}\right]$ galactose at the cell surface by using exogenous galyctosyltransferases ${ }^{14}$. However, endogenous VSRs do not localize to the cell surface and are thus not amendable to exogenously applied modifying enzymes to decipher their function or to trace their transport route in vivo.

VSRs are type I transmembrane proteins and bind ligands via a luminal ligand-binding domain (LBD), whereas their cytosolic tail carries the sorting information for their own transportation $^{15-23}$. They were originally proposed to transport ligands into prevacuoles, nowadays referred to as multivesicular bodies/late endosomes (MVBs/LEs) ${ }^{16,19,21,24-26}$. However, we have recently demonstrated that VSRs bind ligands in the early secretory pathway and instead release them in the trans-Golgi network $(\mathrm{TGN})^{27}$, the early endosome (EE) of plants (TGN/EE) ${ }^{28,29}$. This raised the fundamental questions as to how to where VSRs recycle after ligand release. To address this, we have devised a strategy that utilizes the in vivo interaction of two different antibodyepitope pairs. This allows (a) for the location-specific green fluorescent protein (GFP)-labeling of VSRs in the TGN/EE and (b) for the tracking and lockdown of such labeled VSRs in upstream compartments, upon retrograde recycling. For this, we have translationally fused a variable domain of a lama (Lama paco) heavy-chain antibody $\left(\mathrm{V}_{\mathrm{H}} \mathrm{H}\right)^{27,30}$, termed nanobody $(\mathrm{Nb})$, that was raised against GFP $\left(\mathrm{Nb}_{\mathrm{G}}\right)^{27,31}$ to a VSR $\left(\mathrm{Nb}_{\mathrm{G}}-\mathrm{VSR}\right)$. The other $\mathrm{Nb}$, which was raised against $\alpha$-synuclein $\left(\mathrm{Nb}_{\mathrm{S}}\right)^{32}$, was fused to compartment-specific membrane marker proteins. Finally, we have designed a dual-epitope linker protein, which contains the epitopes of both nanobodies and therefore allows for both, specific GFP-labeling of the $\mathrm{Nb}_{\mathrm{G}}$-tagged VSR via the GFP domain and attachment to $\mathrm{Nb}_{\mathrm{S}}$-tagged compartmental marker proteins via the $\alpha$-synuclein (SYN) epitope. Labeling of $\mathrm{Nb}_{\mathrm{G}}-\mathrm{VSR}$ in the lumen of the TGN/EE is achieved by incubation of $\mathrm{Nb}_{\mathrm{G}}$ and $\mathrm{Nb}_{\mathrm{S}}$ fusion protein-expressing cells with the dual-epitope linker protein GFP-SYN, which is endocytosed and delivered to the TGN/EE. Using this approach, we have traced GFP-labeled VSRs from the TGN/EE back to the cis-Golgi, where we demonstrate their ligand-binding capability. Altogether, these data demonstrate the cycling of VSRs between the Golgi stack and the TGN/EE.

\section{Results}

Post-translational GFP-labeling via endocytosed GFP. The challenge when analyzing bidirectional protein transport of sorting receptors in live-cell imaging studies is to differentiate between anterograde and retrograde transported receptors under steady state conditions. This is particularly true when translational fusions between receptors and fluorescent proteins are used. Here, fluorescent signals become detectable immediately after synthesis and protein folding in the ER and they persist throughout the lifespan of the molecule. Consequently, the localization of the receptor does not provide any information on its transport direction or ligand status (Fig. 1a). An analysis of receptor recycling therefore demands strategies that allow for the specific tracing of those VSRs that have released their ligands in the TGN/ $\mathrm{EE}^{27}$ and are about to be recycled. This requirement is fulfilled if a post-translational labeling strategy is used where signals of the labeled VSRs become first detectable in the TGN/EE (Fig. 1b). To achieve this, we have devised an approach that accounts for both, the target-specificity of the labeling and the intracellular location where the labeling occurs. For this, we have employed a GFPbinding nanobody $\left(\mathrm{Nb}_{\mathrm{G}}\right)^{27,31}$ that is translationally fused to the VSR and we deliver its epitope GFP as the fluorescent labeling agent to the TGN/EE via endocytosis. We produced the labeling GFP as a secretory protein in another population of tobacco mesophyll protoplasts. The resulting GFP-containing culture medium is then used for labeling of the cell population that expresses the $\mathrm{Nb}_{\mathrm{G}}$-tagged VSRs. This strict separation between cells that produce the labeling agent GFP and cells that are used for the labeling ensures that no newly synthesized VSR on its anterograde route is labeled prior to reaching the TGN/EE.

To develop a compartment-specific post-translational GFPlabeling strategy, we firstly decided to employ the established marker proteins $\alpha$-mannosidase 1 (Man1) for the cis-Golgi, sialyltransferase (ST) for the trans-Golgi, SYNTAXIN OF PLANTS (SYP) 61 for the TGN/EE, and the luminal ligandbinding domain-deprived $(\triangle \mathrm{LBD})$ binding protein $80 \mathrm{kDa}$ (BP80) from Pisum sativum for MVB/LE in coexpression experiments to discriminate between the various punctate signals (Supplementary Fig. 1). Next, we generated and tested red fluorescent protein (RFP)-tagged $\mathrm{Nb}_{\mathrm{G}}$ fusion proteins of these markers in tobacco mesophyll protoplasts for post-translational labeling in the TGN/EE (SYP61-RFP-Nb $\left.{ }_{G}\right)$, the MVB/LE $\left(\mathrm{Nb}_{\mathrm{G}^{-}}\right.$ RFP-BP80 $\Delta \mathrm{LBD}$ ), the trans-Golgi $\left(\mathrm{ST}-\mathrm{RFP}-\mathrm{Nb}_{\mathrm{G}}\right)$, the cis-Golgi $\left(\right.$ Man1-RFP-Nb $\left.{ }_{\mathrm{G}}\right)$ and the ER $\left(\mathrm{Nb}_{\mathrm{G}}\right.$-RFP-Calnexin $\left.(\mathrm{CNX})\right)$. After transfection with the respective marker construct, we incubated the cells in GFP-containing culture medium for the endocytic uptake of GFP (endocyt GFP) (Fig. 1c-g). Confocal laserscanning microscopy (CLSM) demonstrated that the endocytosed GFP was trapped by the $\mathrm{Nb}_{\mathrm{G}}$-tagged markers SYP61-RFP- $\mathrm{Nb}_{\mathrm{G}}$ and $\mathrm{Nb}_{\mathrm{G}}-\mathrm{RFP}-\mathrm{BP} 80 \Delta \mathrm{LBD}$ in the TGN/EE and downstream in the MVB/LE, respectively (Fig. 1c, d). In sharp contrast, labeling of the markers in compartments upstream of the TGN/EE like the trans-/cis-Golgi (ST-RFP-Nb ${ }_{\mathrm{G}}$, Man1-RFP-Nb $\left.\mathrm{Nb}_{\mathrm{G}}\right)$ or the ER $\left(\mathrm{Nb}_{\mathrm{G}}-\right.$ RFP-CNX) with endocytosed GFP was never observed (Fig. 1e-g). However, post-translational GFP-labeling based on $\mathrm{Nb}_{\mathrm{G}}$-epitope interaction is also possible in these compartments, if the labeling agent GFP is coexpressed as a secretory protein (Sec-GFP) with the respective $\mathrm{Nb}_{\mathrm{G}}$-fusion proteins (Fig. $1 \mathrm{~h}-\mathrm{j}$ ). This shows that post-translational GFP-labeling via $\mathrm{Nb}_{\mathrm{G}}$-epitope interaction is applicable to $\mathrm{Nb}_{\mathrm{G}}$-tagged proteins in all compartments and furthermore demonstrates that endocytosed GFP alone does not reach locations upstream of the TGN/EE like the cis-/trans-Golgi and the ER. Consequently, this also demonstrates that none of the $\mathrm{Nb}_{\mathrm{G}}$-tagged markers that reside in the ER or the Golgi apparatus, ever reach or cycle through the TGN/EE in order to reach their respective steady state distribution.

Post-translationally labeled VSRs localize to the TGN/EE. In the next step, we applied this post-translational GFP-labeling 
a
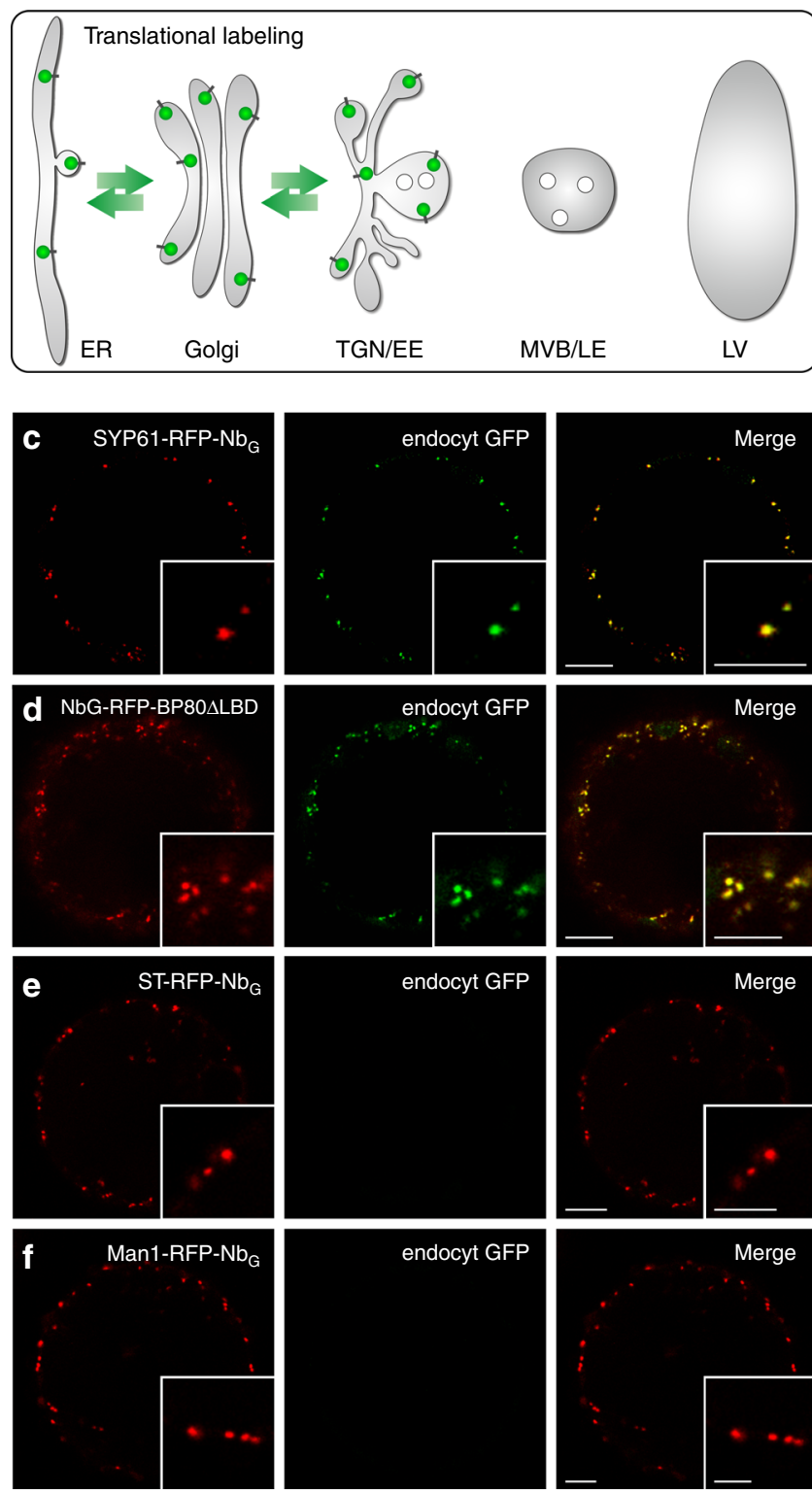

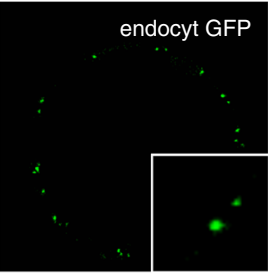

endocyt GFP
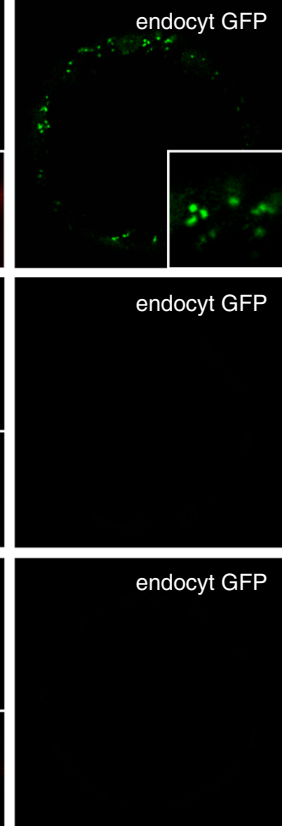
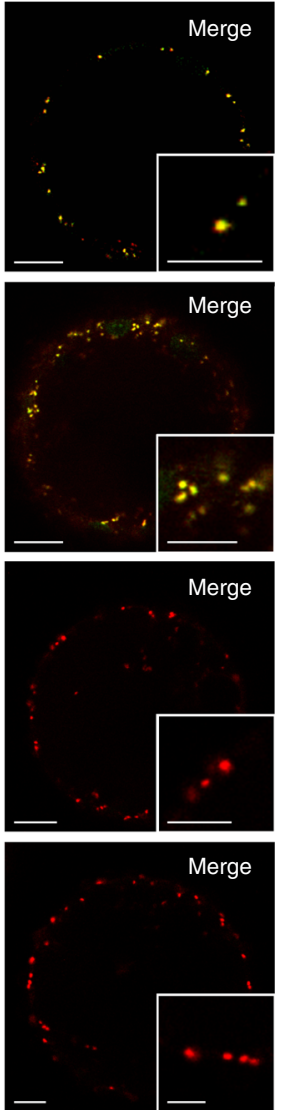

b
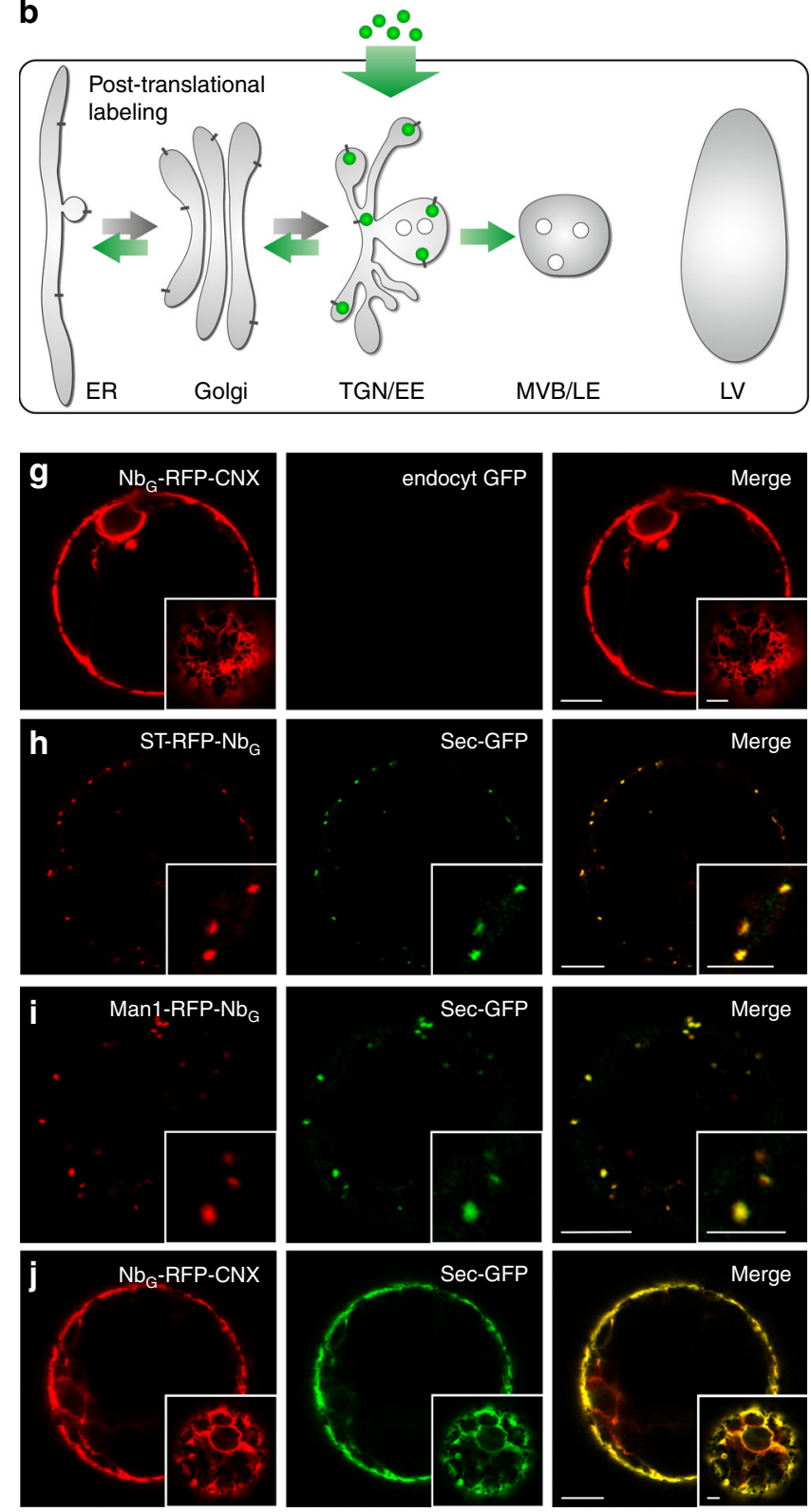

Fig. 1 Post-translational GFP-labeling via nanobody-epitope interaction. a Translational GFP-labeling of VSRs. b Post-translational GFP-labeling of a NbG-

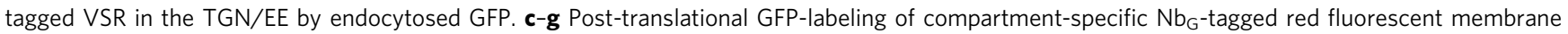
anchors (red) by endocytosed GFP (green) in c the TGN/EE and $\mathbf{d}$ the MVB/LE. Endocytosed GFP does not reach e the trans-Golgi, $\mathbf{f}$ the cis-Golgi nor $\mathbf{g}$ the

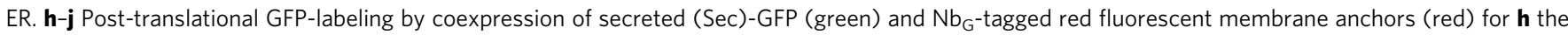
trans-Golgi, $\mathbf{i}$ the cis-Golgi and $\mathbf{j}$ the ER. Insets in $\mathbf{g}$, $\mathbf{j}$ show cortical sections, others show magnifications. Scale bars $10 \mu \mathrm{m}$, insets $5 \mu \mathrm{m}$

protocol to VSRs (Fig. 2a, b). To better judge the labeling efficiency, we tagged a fluorescent $\mathrm{VSR}^{33}$ with the $\mathrm{Nb}_{\mathrm{G}}\left(\mathrm{Nb}_{\mathrm{G}}\right.$-RFPVSR) and performed post-translational GFP-labeling (Fig. 2b). CLSM-based colocalization reveals almost perfectly matching punctate signals of the red $\mathrm{Nb}_{\mathrm{G}}$-RFP-VSR and the green signals from the endocytosed GFP (Fig. 2c, d), demonstrating a high degree of labeling efficiency. However, since $\mathrm{Nb}_{\mathrm{G}}$-RFP-VSR can acquire the labeling GFP only in the TGN/EE, this high degree of colocalization furthermore suggests that under steady state conditions almost all of the $\mathrm{Nb}_{\mathrm{G}}$-RFP-VSR molecules had already reached the TGN/EE, at least once.

We have recently demonstrated that VSRs bind their ligands in the ER, in the cis- and trans-Golgi, but release their ligands in the $\mathrm{TGN} / \mathrm{EE}^{27}$. Therefore, we hypothesized that the ligand-free receptors that were post-translationally labeled with endocytosed GFP in the TGN/EE would recycle to an upstream compartment for ligand reloading. In such a scenario, we would then expect to detect a population of labeled VSRs in a compartment upstream of the TGN/EE. To precisely define the VSR localizations we next post-translationally labeled non-fluorescent $\mathrm{Nb}_{\mathrm{G}}$-tagged VSRs $\left(\mathrm{Nb}_{\mathrm{G}}-\mathrm{VSR}\right)$ with endocytosed GFP and tested for colocalization with established red fluorescent compartmental markers (Fig. 2e, f) for the TGN/EE (RFP-SYP61), the MVB/LE and vacuole (Aleu-RFP), trans- and cis-Golgi (ST-RFP and Man1$\mathrm{RFP}$, respectively) and for the ER (RFP-CNX) in coexpression experiments (Fig. $2 \mathrm{~g}-\mathrm{m}$ ). The post-translationally labeled $\mathrm{Nb}_{\mathrm{G}^{-}}$ VSRs colocalized with the TGN/EE marker (Fig. 2g). Surprisingly, the post-translationally labeled $\mathrm{Nb}_{\mathrm{G}}$-VSRs neither colocalized 
with the MVB/LE and vacuole marker Aleu-RFP (Fig. 2h, i) nor with markers for upstream compartments like the trans- and cisGolgi or the ER (Fig. 2j-m). This steady state localization of $\mathrm{Nb}_{\mathrm{G}^{-}}$ VSR at the TGN/EE rather than at the MVB/LE, as is commonly assumed, is not restricted to post-translationally labeled $\mathrm{Nb}_{\mathrm{G}}$ VSRs, it is also seen in control experiments using the fluorescent full-length receptor fusion protein $\mathrm{Nb}_{\mathrm{G}}$-RFP-VSR (Supplementary Fig. 2). The differential localization of these full-length VSRs
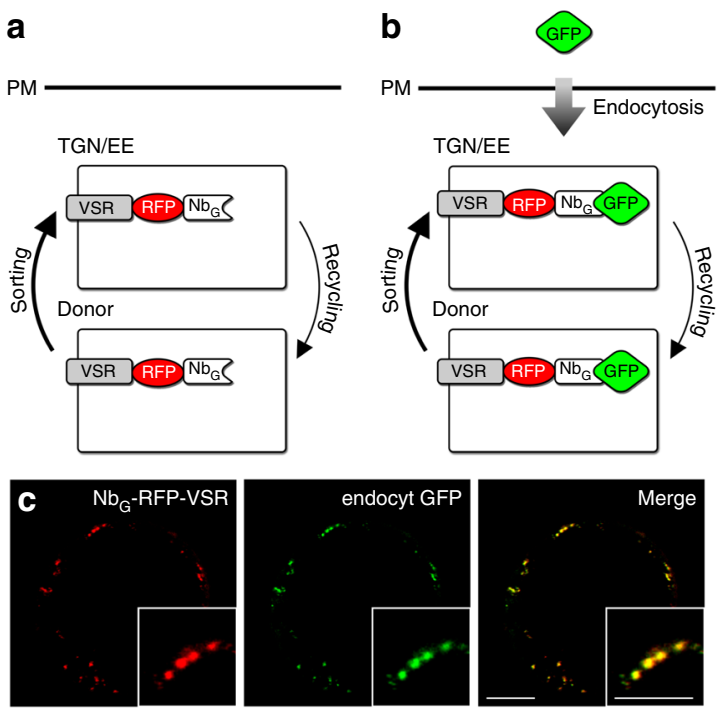

d

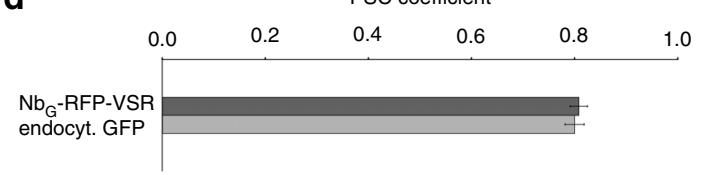

e
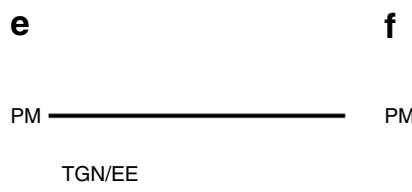

f
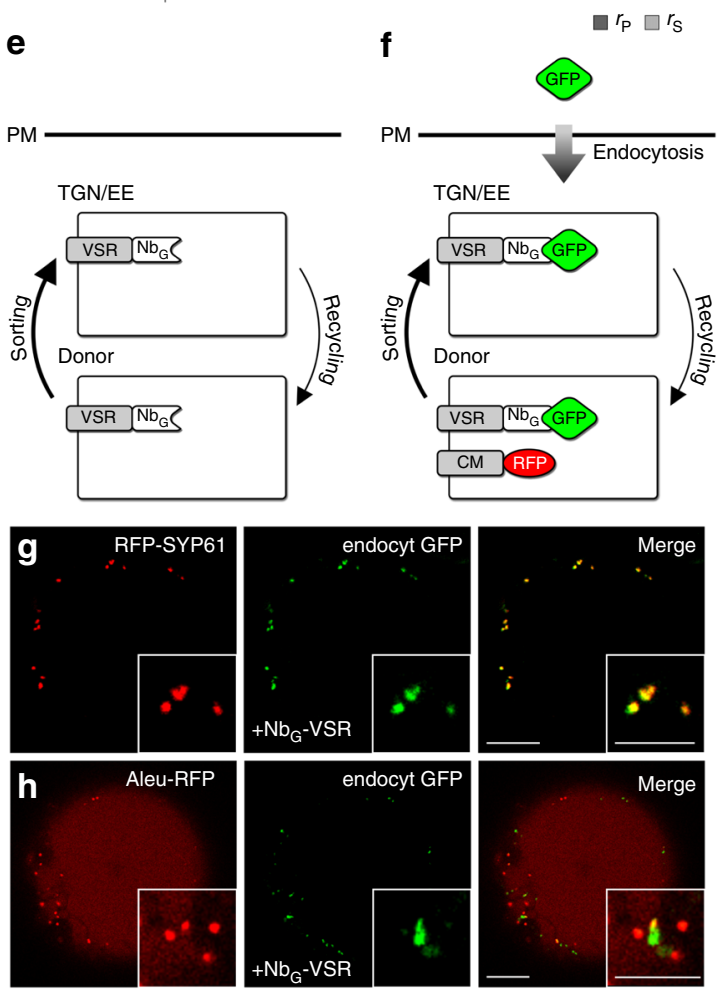

i

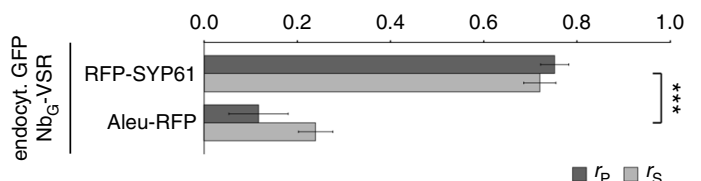

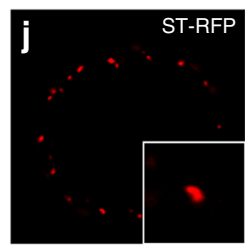
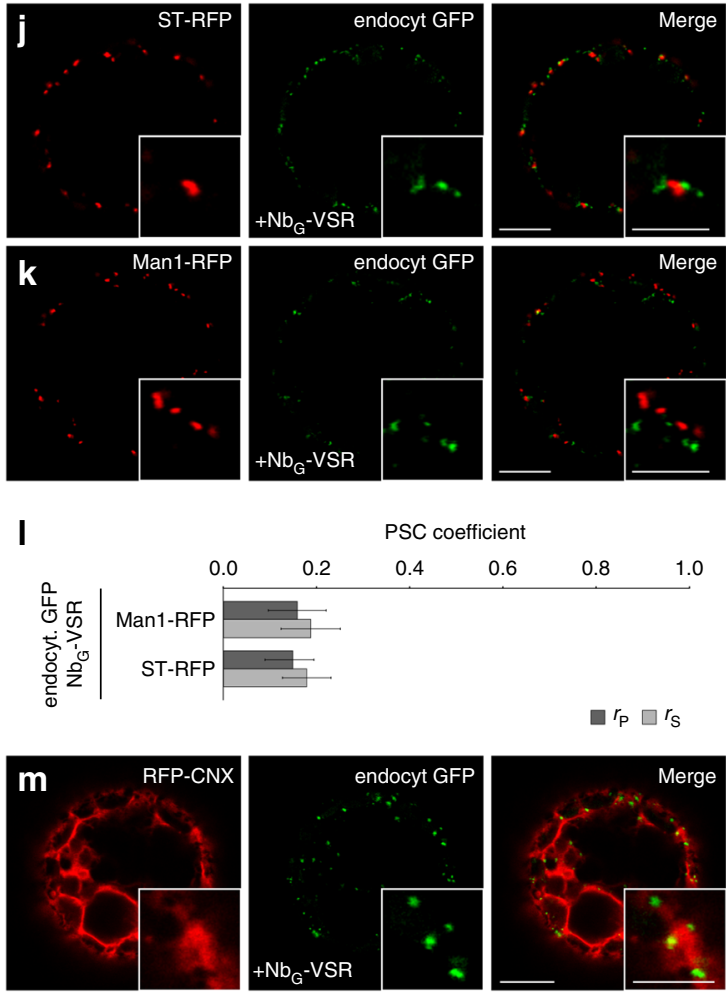
and LBD-lacking MVB/LE markers of the RFP/GFP-BP80 $\Delta \mathrm{LBD}$ type, therefore suggests that the presence of the LBD is required for both, the ligand-binding capability and for the correct transport of the receptor.

Nanobody-triggered lockdown of recycled VSRs. One possible explanation for the TGN/EE-localization of VSRs under steady state conditions is that VSRs do not recycle to reload ligands. Such a one-way transport mode was suggested for members of the receptor homology region-transmembrane domain-RING-H2 (RMR) receptor family, which sort proteins to the protein storage vacuole $^{34}$. However, considering that the TGN/EE is expected to be the recycling point of a bidirectional transport system ${ }^{27,35}$, the TGN/EE-localization of cycling VSRs may indicate that anterograde transport is faster than the subsequent recycling step. To test for his hypothesis, we have devised a strategy that allows for the specific detection of recycled receptors in compartments upstream of the TGN/EE by blocking their further export and onward forwarding upon completion of recycling. For this, we have combined the nanobody-mediated post-translational labeling of recycling VSRs in the TGN/EE with an approach for compartment-specific lockdown of these labeled VSRs via a nanobody-epitope interaction that is triggered by a second nanobody-epitope pair (Fig. 3a-c).

Hereto, we translationally fused a nanobody that is directed against the mammalian $\alpha$-synuclein $\left(\mathrm{Nb}_{\mathrm{S}}\right)$ to red fluorescent compartment-specific markers (CM-RFP-Nb ${ }_{S}$ ) and we fused its corresponding epitope termed SYN, which is a sequence of 23 amino acids, to GFP (GFP-SYN). Endocytic uptake of this dualepitope linker as the labeling agent by cells coexpressing $\mathrm{Nb}_{\mathrm{G}^{-}}$ VSRs and $\mathrm{Nb}_{\mathrm{s}}$-tagged compartmental markers was then expected to firstly label $\mathrm{Nb}_{\mathrm{G}}$-VSRs in the TGN/EE and then to trigger an in vivo crosslink between the SYN epitope of the GFP-SYNlabeled VSR and the $\mathrm{Nb}_{\mathrm{s}}$-tagged compartmental marker in the compartmental lumen.

This complex strategy required that we first test whether $\mathrm{Nb}_{\mathrm{S}}$ interacts with the SYN epitope in the lumen of secretory pathway compartments. To this end, we developed an assay for analyzing protein-protein interaction in vivo. This assay is based on the simultaneous use of a quantifiable soluble secretory reporter with a soluble vacuolar protein, each of which carries either the nanobody or the epitope, respectively. In this approach, the interaction occurring between the $\mathrm{Nb}_{\mathrm{S}}$ and the epitope triggers the attachment of the vacuolar sorting signal to the secretory reporter and consequently, its transport to the lytic vacuole via the vacuolar sorting machinery (Fig. 3d, e).

We therefore tagged the secretory reporter $\alpha$-amylase from barley (Hordeum vulgare) ${ }^{36}$ with the SYN epitope (amylase-SYN) and employed the vacuolar reporter Aleu-RFP as a $\mathrm{Nb}_{\text {s-fusion }}$ protein (Aleu-RFP-Nb ${ }_{S}$ ). Quantitative transport analysis of the secretory amylase-SYN in tobacco mesophyll protoplasts shows that its secretion is drastically reduced by the coexpressed vacuolar Aleu-RFP-Nb $\mathrm{S}_{\mathrm{S}}$ (Fig. 3f), suggesting an interaction between the $\mathrm{Nb}_{S}$ and the SYN epitope. In the next step, we tested the functionality of $\mathrm{Nb}_{\mathrm{S}}$ in the context of the compartmentspecific membrane anchors for the ER, cis- and trans-Golgi and the TGN/EE. For this, we fused the $\mathrm{Nb}_{\mathrm{s}}$ to RFP-CNX $\left(\mathrm{Nb}_{\mathrm{s}}-\mathrm{RFP}\right.$ CNX), Man1-RFP (Man1-RFP-Nbs), ST-RFP (ST-RFP-Nb ${ }_{S}$ ) and SYP61-RFP (SYP61-RFP-Nbs) and verified firstly their correct location in colocalization experiments with their respective GFPtagged counterpart (Supplementary Fig. 3). Second, we tested their ability to bind the dual-epitope linker GFP-SYN (Fig. 3g-j). To do this, we immunoprecipitated the above-mentioned marker proteins and their $\mathrm{Nb}_{\mathrm{s}}$-tagged pendants, the anchors, with RFP antibodies in bead-binding assays and subjected all of them to the GFP-SYN-containing culture medium from GFP-SYN-secreting protoplasts. The immunoblot analysis of the precipitates revealed that all of the $\mathrm{Nb}_{\mathrm{s}}$-tagged anchors co-immunoprecipitated the SYN epitope-tagged GFP, whilst this molecule was absent in precipitates from markers lacking the $\mathrm{Nb}_{\mathrm{s}}$. To rule out that on the other side the SYN epitope from GFP-SYN perturbs the interaction between the GFP epitope and $\mathrm{Nb}_{\mathrm{G}}$, we performed comparative co-immunoprecipitation experiments using beadbound $\mathrm{Nb}_{\mathrm{G}}$-VSR with either secreted GFP or secreted GFP-SYN, to show that the $\mathrm{Nb}_{\mathrm{G}}$-VSR binds GFP and GFP-SYN to comparable levels (Fig. 3k).

Finally, we performed colocalization experiments of GFP-SYNlabeled $\mathrm{Nb}_{\mathrm{G}}$-VSRs with the markers for the TGN/EE, trans- and cis-Golgi and the ER, showing that the labeling of $\mathrm{Nb}_{\mathrm{G}}$-VSR with GFP-SYN does not alter the localization of the labeled VSR (Supplementary Fig. 4, compare to Fig. 2).

Altogether, these results show that this second $\mathrm{Nb}_{\mathrm{S}}-\mathrm{SYN}$ nanobody-epitope pair is suitable for triggering a stable linkage between proteins, both in vitro and in vivo. The results also demonstrate that each epitope of GFP-SYN is accessible for $\mathrm{Nb}_{\mathrm{G}}$ or $\mathrm{Nb}_{\mathrm{S}}$ interaction.

The cis-Golgi is the target of the VSR recycling route. To apply the strategy for nanobody-triggered lockdown to the analysis of VSR recycling, we have subjected cells that coexpress $\mathrm{Nb}_{\mathrm{G}}$-tagged VSRs with the above-mentioned $\mathrm{Nb}_{\mathrm{S}}$-tagged anchors to posttranslational VSR-labeling using the endocytosed dual-epitope linker GFP-SYN (Fig. 4). First labeling of $\mathrm{Nb}_{\mathrm{G}}$-VSRs in cells coexpressing the TGN/EE anchor SYP61-RFP-Nb resulted in almost perfect colocalization of both signals (Fig. 4a), as was seen before when the non-tagged TGN/EE marker was used (Fig. 4b). This suggested that the endocytosed $\mathrm{Nb}_{\mathrm{G}}$-VSR-labeling agent GFP-SYN does not generally perturb membrane trafficking events in the presence of the $\mathrm{Nb}_{\mathrm{S}}$-tagged membrane anchor. In the next step, we subjected cells that coexpressed the anchors for the upstream compartments to this procedure. Here, the localization of the GFP-SYN-labeled $\mathrm{Nb}_{\mathrm{G}}$-VSRs shifted drastically and now colocalized with the trans-Golgi anchor ST-RFP-NbS (Fig. 4c, d, compare to 4b). Likewise, localization of GFP-SYNlabeled $\mathrm{Nb}_{\mathrm{G}}$-VSRs shifted strongly towards the cis-Golgi when the anchor Man1-RFP-Nb sas used for the lockdown of the labeled

Fig. 2 Localization of post-translationally labeled $\mathrm{Nb}_{\mathrm{G}}$-tagged VSRs. a Cycling $\mathrm{Nb}_{\mathrm{G}}$-tagged red fluorescent VSRs are b post-translationally labeled by endocytosed GFP. c GFP-labeled red fluorescent $\mathrm{Nb}_{\mathrm{G}}$-tagged VSRs. d Pearson's $\left(r_{\mathrm{P}}\right)$ and Spearman's $\left(r_{\mathrm{s}}\right)$ correlation (PSC) coefficients of Nb ${ }_{\mathrm{G}}$-RFP-VSRs and labeling GFP. Data are presented as average \pm s.e.m. of 10 individual cells. The graph shows a representative sample of two independent experiments. e, $\mathbf{f}$ Colocalization of post-translationally GFP-labeled non-fluorescent cycling $\mathrm{Nb}_{\mathrm{G}}$-tagged $\mathrm{VSRs}\left(\mathrm{Nb}_{\mathrm{G}}-\mathrm{VSR}\right.$ ) with red fluorescent compartmental markers (CM) for $\mathbf{g}$, $\mathbf{i}$ the TGN/EE, $\mathbf{h}, \mathbf{i}$ MVBs/LEs and vacuole, $\mathbf{j}$, I the trans-/ and $\mathbf{k}$, I cis-Golgi and $\mathbf{m}$ the ER. i, I PSC coefficients of the labeled Nb ${ }_{G}-V_{S R}$ and coexpressed markers RFP-SYP61, Aleu-RFP, Man1-RFP and ST-RFP are calculated and presented as in d. Graphs show a representative sample of two independent experiments. Labeled $\mathrm{Nb}_{\mathrm{G}}$-VSRs colocalize with the TGN/EE marker but not with markers for MVB/LE and vacuole and the cis-/trans-Golgi. $\mathbf{i}$ Significance was calculated using unpaired, two tailed $t$-test $\left(n=10,{ }^{\star \star \star} P<0.001\right)$. Scale bars $10 \mu \mathrm{m}$, insets $5 \mu \mathrm{m}$. Insets show magnifications 
$\mathrm{Nb}_{\mathrm{G}}$-VSR (Fig. 4e, f, compare to $4 \mathrm{~b}$ ). The colocalization of GFPSYN-labeled VSRs and the $\mathrm{Nb}_{\mathrm{S}}$-tagged anchors for the trans- and cis-Golgi strictly depends on the presence of the second nanobody-epitope pair and was never observed when marker pendants without the $\mathrm{Nb}_{\mathrm{S}}$-tag were used (Fig. $4 \mathrm{~d}$, f, compare to

a

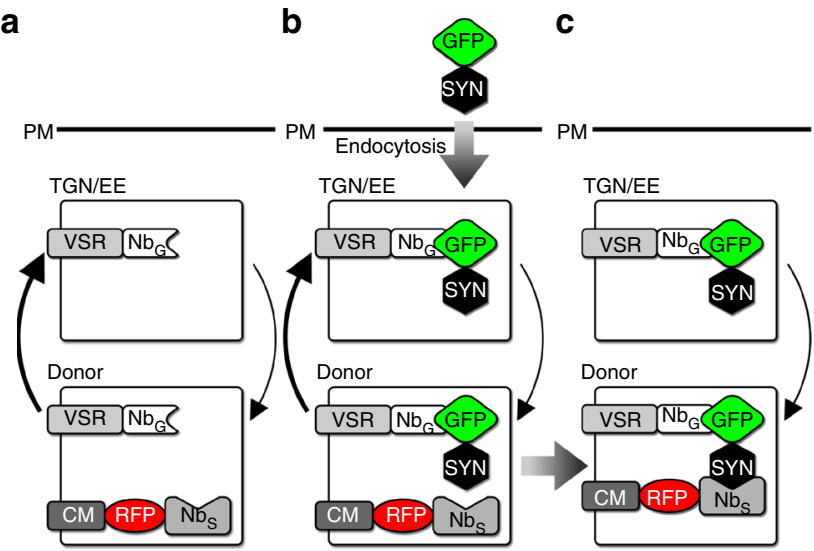

d

e
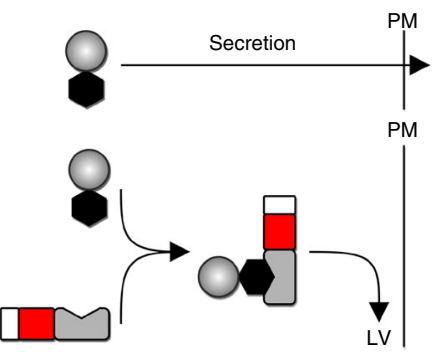

amy-SYN

पM Aleu-RFP-Nbs g

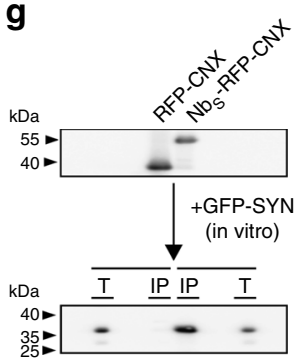

i

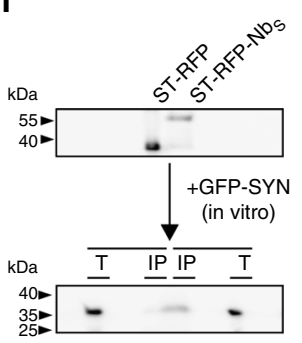

k

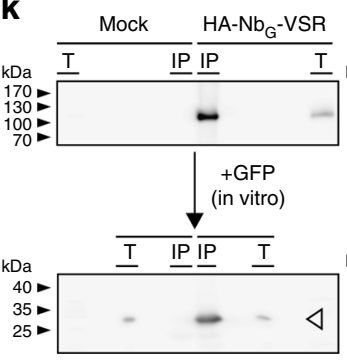

f

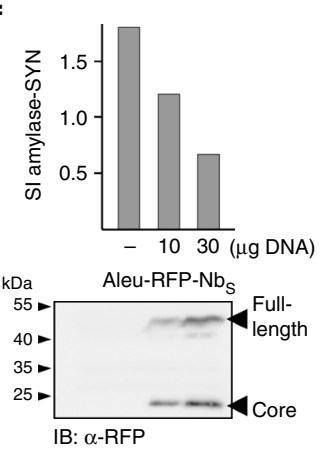

Supplementary Figs. 4 and 5). This suggests, that the VSRs did indeed recycle from the TGN/EE to the Golgi stack. To rule out that the GFP-SYN triggered crosslink between $\mathrm{Nb}_{\mathrm{G}}-$ VSR and STRFP-Nb $b_{S}$ or Man1-RFP-Nb altered the Golgi localization of the anchors in these experiments, we used the fungal toxin brefeldin A (BFA) as a diagnostic tool to confirm the Golgi localization of both anchors. In tobacco, BFA causes a fusion between Golgi stacks and the $\mathrm{ER}^{37}$ thereby triggering a shift of signals from Golgi anchors to the ER. After BFA-treatment, the punctate signals from crosslinked GFP-SYN-labeled VSR-cis- and transGolgi cisternal anchors became detectable in the nuclear envelope (Fig. 4g, h). This demonstrated that the lockdown did not alter the localization of the Golgi anchors. In sharp contrast, a colocalization between GFP-SYN-labeled $\mathrm{Nb}_{\mathrm{G}}$-VSRs and the ER anchor $\mathrm{Nb}_{\mathrm{S}}$-RFP-CNX was never observed (Fig. 4i). This, however, indicates that VSRs do not recycle to upstream compartments further than the cis-Golgi.

Recycled VSRs reload ligands in the cis-Golgi. We have previously used the soluble model ligand Aleu-RFP together with a soluble $\mathrm{Nb}_{\mathrm{G}}$-tagged LBD of a VSR that was anchored to a GFPtagged membrane marker by nanobody-epitope interaction. There, ligand binding to the anchored LBD in a given compartment was visualized through coaccummulation/colocalization of the otherwise passing ligands ${ }^{27}$. We have now extended this visualization concept to the analysis of the ligand-binding capabilities of recycled full-length VSRs in the Golgi (Fig. 5a-d).

Hereto, we performed a cis-Golgi-specific dual-epitope triggered VSR lockdown in cells, coexpressing the vacuolar reporter Aleu-RFP, $\mathrm{Nb}_{\mathrm{G}}-\mathrm{VSR}$, Man1-Nb , which is used for the lockdown and Man1-blue fluorescent protein (BFP)2, which serves as neutral marker to verify the localization (Fig. 5e). The analysis clearly shows the triple-overlap of the fluorescence signals from the vacuolar reporter Aleu-RFP with the recycled GFP-SYNlabeled $\mathrm{Nb}_{\mathrm{G}}$-tagged VSR and the cis-Golgi marker Man1-BFP2, demonstrating the interaction between the recycled VSRs and the ligand in the cis-Golgi. The same was also seen when the VSR lockdown was performed in the trans-Golgi by using ST-Nb (Supplementary Fig. 6a). In sharp contrast, no colocalization between VSRs and ligands are seen in controls without the $\mathrm{Nb}_{\mathrm{S}}$ SYN triggered VSR lockdown: neither in the absence of the $\mathrm{Nb}_{\mathrm{S}^{-}}$

Fig. 3 Nanobody-triggered lockdown of recycled VSRs. a Coexpression of $\mathrm{Nb}_{\mathrm{G}}$-VSRs with red fluorescent $\mathrm{Nb}_{\mathrm{S}}$-tagged compartmental markers (anchors) and $\mathbf{b}$ post-translational labeling with the dual-epitope GFP-SYN in the TGN/EE to $\mathbf{c}$ anchor VSRs upon recycling. $\mathbf{d}$, e $\mathrm{Nb}_{S}-\mathrm{SYN}$ epitope interaction occurs in the endomembrane system. d SYN epitope-tagged secreted amylase (amy-SYN) is e rerouted to the lytic vacuole (LV) upon Aleu-RFP-Nbs triggers attachment of the vacuolar sorting signal (Aleu). f Coexpression of amy-SYN with different amounts of Aleu-RFP-Nbs. Upper panel: secretion index (SI); lower panel: corresponding immunoblot $(\alpha-$ RFP). g-j Co-immunoprecipitations revealing $\mathrm{Nb}_{S}-\mathrm{SYN}$ epitope interaction. RFP-tagged markers and anchors for $\mathbf{g}$ ER, $\mathbf{h}$ cis-Golgi, $\mathbf{i}$ trans-Golgi and $\mathbf{j}$ TGN/EE were immunoprecipitated (IP, $\alpha$-RFP), incubated with GFP-SYN and immunoblotted (IB). Total extracts ( $T$ ) and immunoprecipitates (IP) were probed to detect markers, anchors ( $\alpha$-RFP) and co-precipitated GFPSYN $\left(\alpha\right.$-GFP). k Co-immunoprecipitation revealing $\mathrm{Nb}_{\mathrm{G}}$-GFP epitope interaction. Expressed $\mathrm{Nb}_{\mathrm{G}}$-VSRs or samples from mock-transfected cells were immunoprecipitated (IP, $\alpha-H A)$, incubated with GFP or GFP-SYN and immunoblotted (IB). Total extracts ( $T$ ) and immunoprecipitates (IP) were probed to detect VSRs ( $\alpha-H A)$ and co-precipitated GFP (white arrowhead) or GFP-SYN (black arrowhead) ( $\alpha$-GFP), respectively 
tagged anchor (Fig. 5f, Supplementary Fig. 6b) nor in the absence of the SYN epitope, when GFP is used for the labeling instead of GFP-SYN (Fig. 5g, Supplementary Fig. 6c). This was to be expected, since "free" labeled VSRs localize to the TGN/EE in
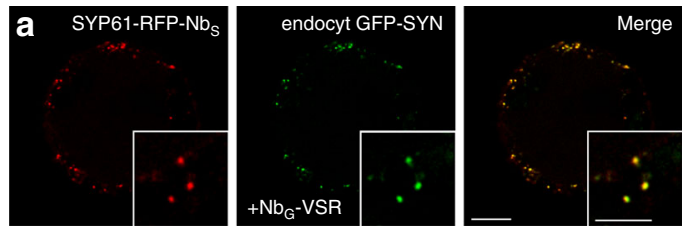
b
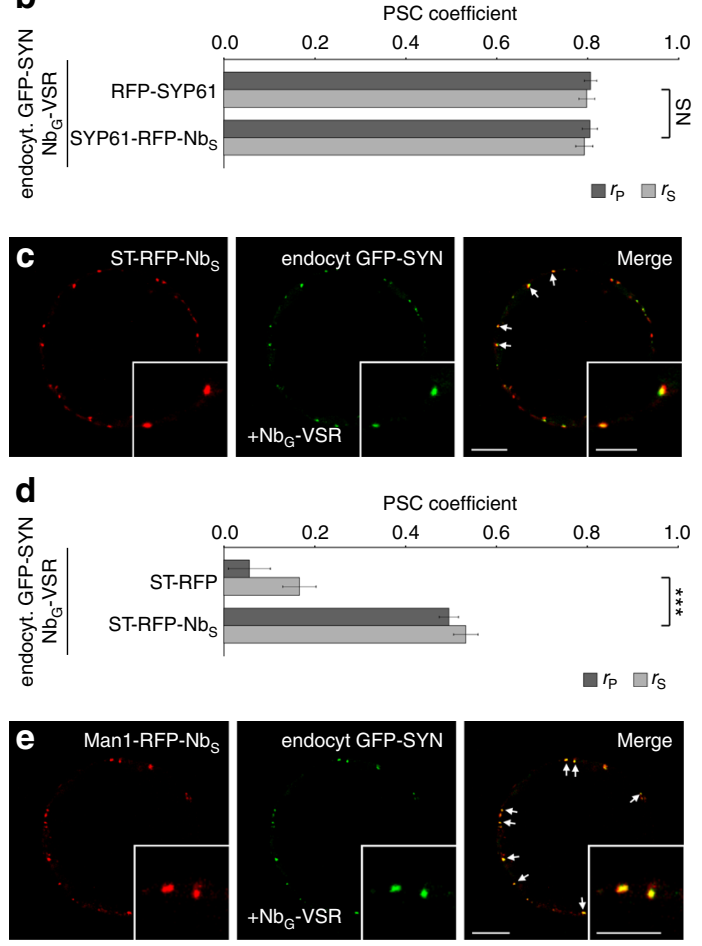

0.4

$0.6 \quad 0.8$ 1.0 f
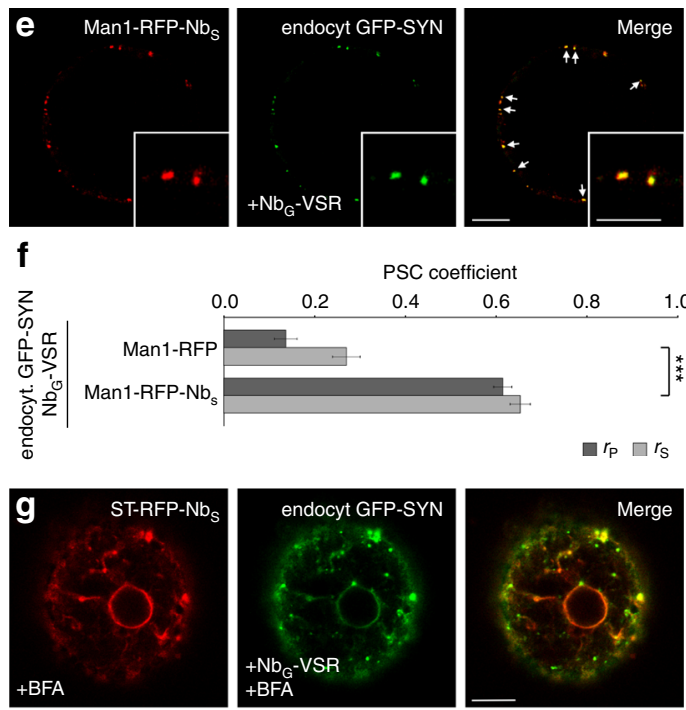

$\square r_{\mathrm{P}} \square r_{\mathrm{S}}$
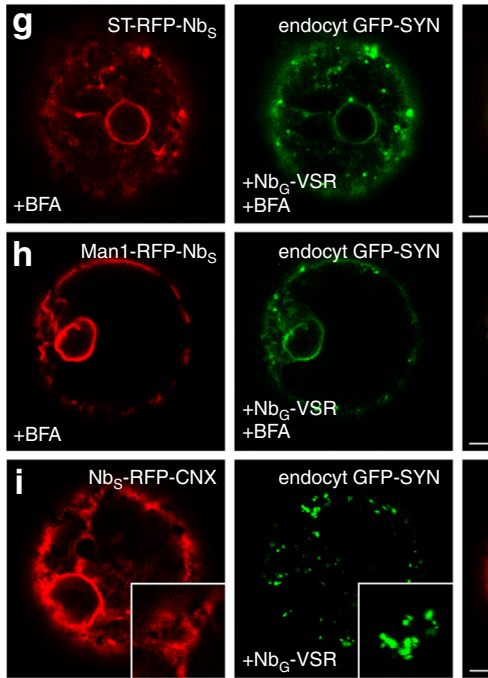

these controls (compare to Fig. 2g, i and Supplementary Fig. 4a), a compartment that does not provide ligand-binding conditions ${ }^{27}$.

\section{Discussion}

Being only about 125 amino acids long, nanobodies are the smallest entities, capable of specific antigen recognition and binding $^{38}$. Nanobodies are therefore ideally suited for the generation of genetically encoded molecular tools for the identification, localization and manipulation of protein function in living cells for basic research and applied sciences ${ }^{39,40}$

We have previously generated VSR sensors for a compartmentspecific analysis of VSR-ligand interactions ${ }^{27}$. They self-assemble from soluble VSR_LBD-Nb ${ }_{\mathrm{G}}$ fusion proteins and GFP-tagged compartment-specific membrane anchors. Using this approach, we have demonstrated that VSRs bind ligands in the ER, the cisand the trans-Golgi and ultimately release ligands in the TGN/ $\mathrm{EE}^{27}$, thereby opening the question about the fate of VSRs after this step. The analysis of bidirectional receptor transport and receptor recycling in particular, however, is technically most challenging in living cells. It requires molecular tools that permit the strict differentiation between VSRs from the anterograde and the retrograde trafficking route.

To overcome these constraints, we have taken advantage of the TGN as also being the EE by incubating $\mathrm{Nb}_{\mathrm{G}}$-VSR-expressing cells with exogenously applied protoplast-secreted GFP to trigger compartment-specific labeling of VSRs in the TGN/EE by its endocytic uptake. This ensures labeling of only those VSRs that have reached the recycling point, whereas newly synthesized VSRs from the anterograde route remain invisible. Most interesting for future application however is the simultaneous use of two different $\mathrm{Nb}$ epitope pairs in vivo. This allows for triggering a protein-specific lockdown of recycled $\mathrm{Nb}_{\mathrm{G}}$-VSRs at $\mathrm{Nb}_{\mathrm{s}}$-tagged membrane proteins by the exogenously applied dual-epitope linker peptide GFP-SYN. Using this strategy, we demonstrated retrograde VSR recycling to the cis-Golgi as being the most distant compartment upstream of the TGN/EE. Together with the fact that VSRs reload ligands after recycling, this supports the concept of bidirectional VSR transport.

On the basis of our investigations, we now present the following concept for the operation of VSR-mediated vacuolar sorting in the plant endomembrane system (Fig. 6). Newly synthesized VSRs bind ligands in the early secretory pathway $23,27,41,42$ at neutral $\mathrm{pH}^{21,26,43}$ and transport them to the TGN/EE, where they ultimately release their ligands ${ }^{27}$, due to a shift in compartmental $\mathrm{pH}$. The TGN/EE is the most acidic compartment en route to the vacuole $^{26,43,44}$, since it harbors characteristic V-ATPases ${ }^{28}$ that are absent from the MVBs $/ \mathrm{LEs}^{45}$, thus preventing further acidification. Therefore, the locations for binding and release of ligands are in agreement with the initially recorded $\mathrm{pH}$ dependency for VSR-

Fig. 4 The cis-Golgi stack is the target of VSR recycling. GFP-SYN-labeled $\mathrm{Nb}_{G}-$ VSR is locked to the anchors in a the TGN/EE (SYP61-RFP-Nbs), and after recycling to $\mathbf{c}$ trans-Golgi (ST-RFP-Nbs) and e cis-Golgi (Man1-RFP$\mathrm{Nb}_{S}$ ) anchors but does not reach $\mathbf{i}$ the ER anchor $\mathrm{Nb}_{S}-\mathrm{RFP}-\mathrm{CNX}$. PSC coefficients of the labeled $\mathrm{Nb}_{\mathrm{G}}-\mathrm{VSR}$ with $\mathbf{b}$ the marker Syp61-RFP or the anchor Syp61-RFP-Nbs, presented/calculated as in Fig. $2 \mathrm{~g}$ with $n=10, P \geq$ 0.05 , NS not significant, $\mathbf{d}$ the marker ST-RFP or the anchor ST-RFP-Nb presented/calculated as above with $n=10,{ }^{\star \star \star} P<0.001$ and $\mathbf{f}$ the marker Man1-RFP or the anchor Man1-RFP-Nbs, presented/calculated as in $\mathbf{d}$. Graphs show a representative sample of two independent experiments. $\mathbf{g}, \mathbf{h}$ BFA-treatment of samples from $\mathbf{c}$, e for $1 \mathrm{~h}$ at $20 \mu \mathrm{M}$ triggers fusion of Golgi with ER, verifying Golgi localization of locked VSRs from c, e. Scale bars 10 $\mu \mathrm{m}$, insets $5 \mu \mathrm{m}$, showing magnifications 
a

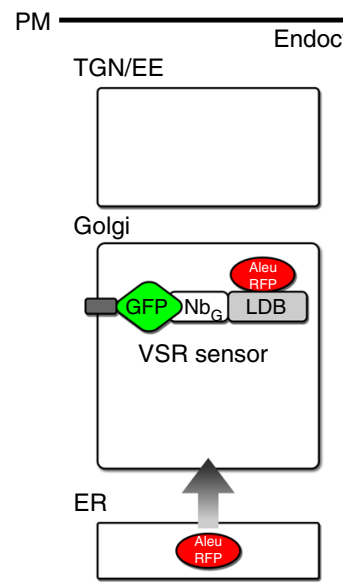

b

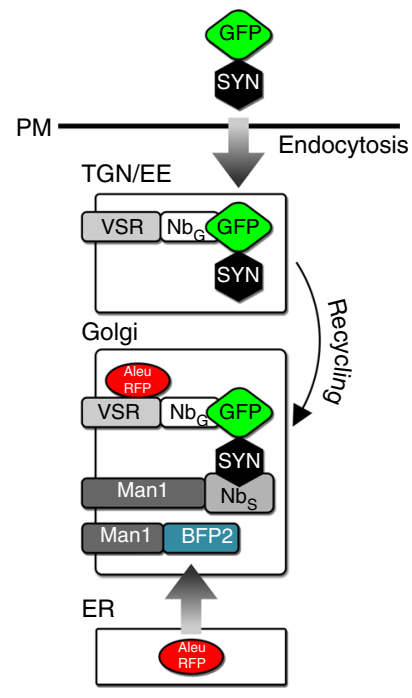

C

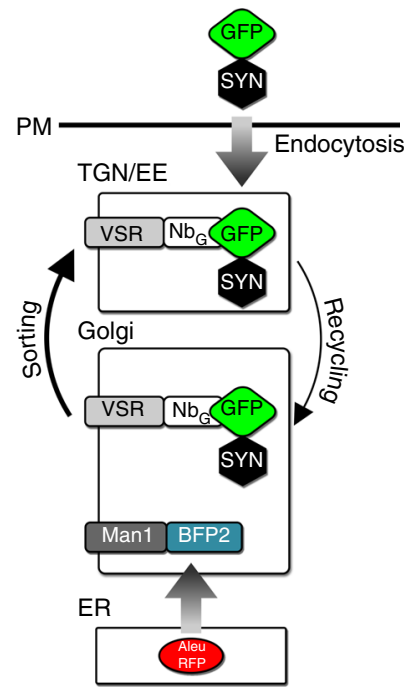

d

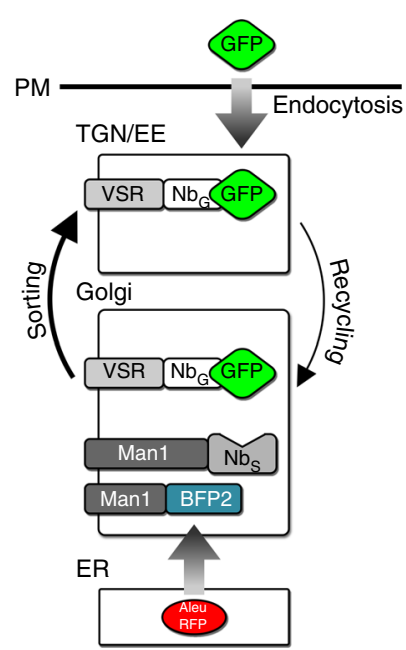

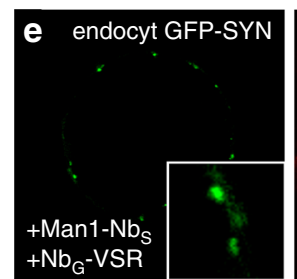
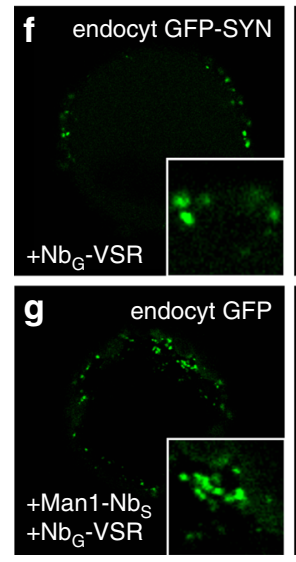
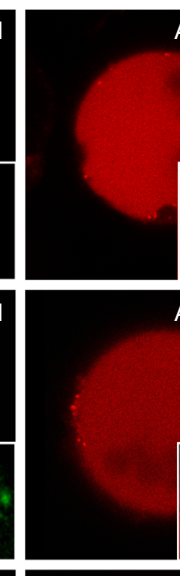

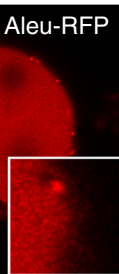

Aleu-RFP
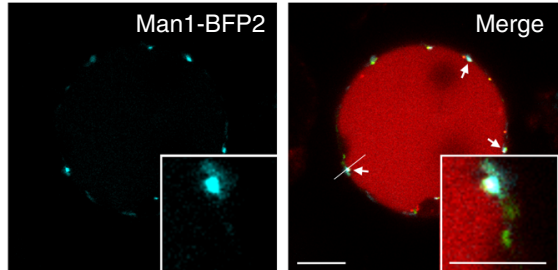

100
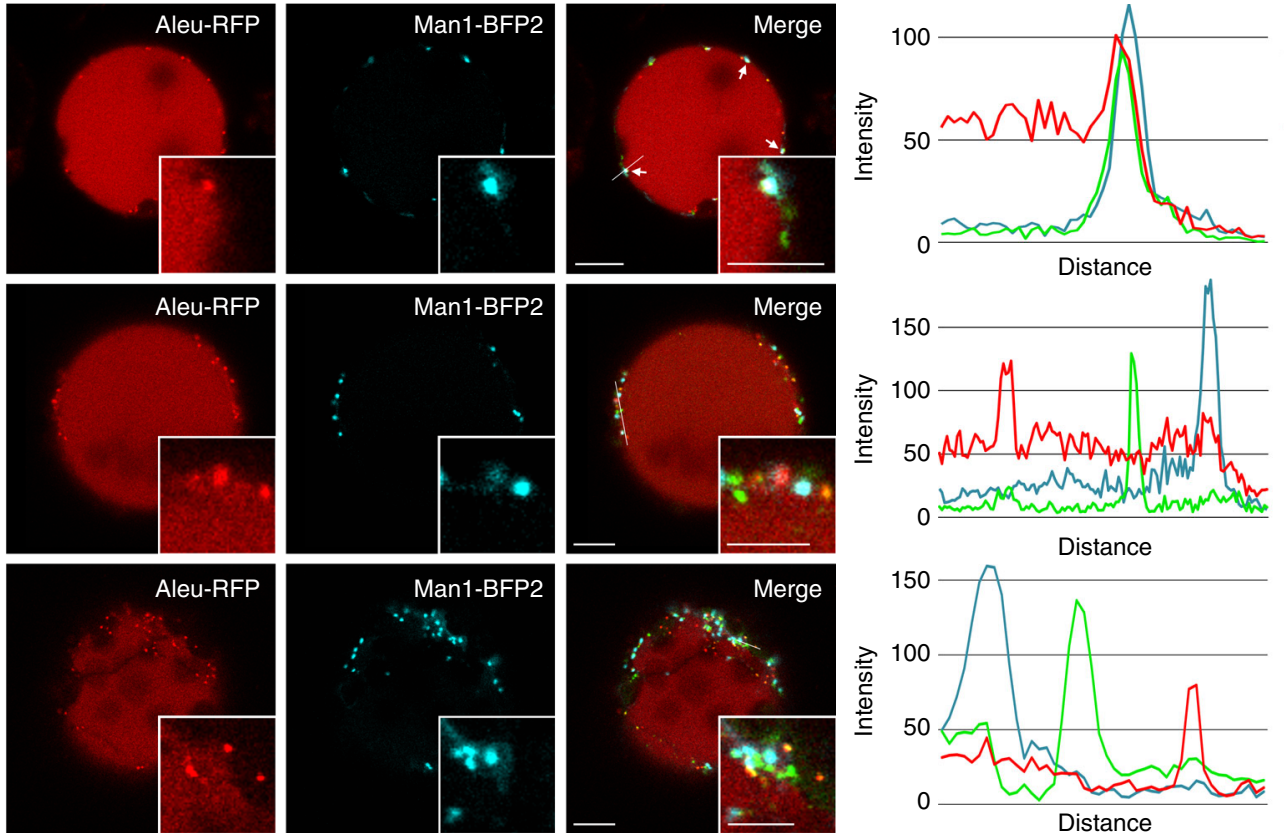

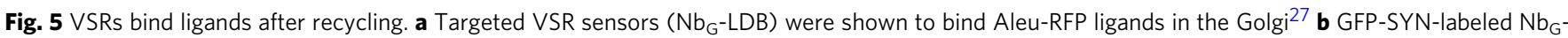
VSRs are locked to the anchor Man1-Nbs in the cis-Golgi, positively identified by the marker Man1-BFP2. Ligand-binding of recycled full-length VSRs is assessed by colocalization with ligands (Aleu-RFP). Controls with cycling VSRs that lack $\mathbf{c}$ the anchor or $\mathbf{d}$ the SYN epitope at the labeling GFP for the VSR

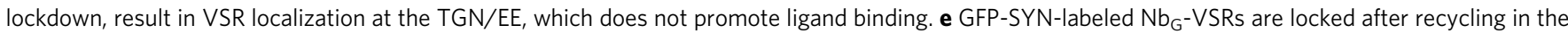
cis-Golgi and colocalize with the Golgi marker Man1-BFP2 and bind the ligand Aleu-RFP, as shown by the overlapping signal peaks in the line intensity plot (see b). f, $\mathbf{g}$ Not locked VSRs (see $\mathbf{c}$ and $\mathbf{d}$ ) do not localize to the Golgi and thus do not bind the ligand Aleu-RFP as judged by the separated peaks in the line intensity plots. Scale bars $10 \mu \mathrm{m}$, insets $5 \mu \mathrm{m}$, showing magnifications

ligand interactions in vitro ${ }^{21}$. After release in the TGN/EE, ligands progress without further involvement of VSRs onwards to the lytic vacuole by default ${ }^{27}$. This occurs due to a maturation event of the $\mathrm{TGN} / \mathrm{EE}$ that results in the biogenesis of a $\mathrm{MVB} / \mathrm{LE}^{46,47}$. While fusion of the MVB/LE with the vacuole represents the final step in the vacuolar delivery of ligands ${ }^{46}$ it is unrelated to VSR function. VSRs, however, recycle from the TGN/EE back to the cis-Golgi, for ligand reloading and renewed rounds of ligand delivery to the TGN/EE. Considering the lifespan of VSRs greatly exceeding the time it takes for a round of transport, it is plausible to assume that cycling VSRs bear the brunt of the ligand transport from the Golgi to the TGN/EE with only a minor contribution of de novo synthesized VSRs, binding their ligands in the ER.

\section{Methods}

Plant materials. Nicotiana tabacum L. SR1 was grown on Murashige and Skoog medium supplemented with $2 \%(\mathrm{w} / \mathrm{v})$ sucrose, $0.5 \mathrm{~g} \mathrm{~L}^{-1} \mathrm{MES}$ and $0.8 \%(\mathrm{w} / \mathrm{v})$ Agar at $\mathrm{pH} 5.7$ in $16 / 8 \mathrm{~h}$ light-dark cycles at $22^{\circ} \mathrm{C}$.

Plasmid constructs. All constructs are given in Supplementary Table 1. DNA manipulations were performed according to established procedures, using pGree$\mathrm{nII}^{48}$-based vectors and Escherichia coli MC1061. An anti-SYN nanobody sequence was generated by reverse translation of the amino acid sequence NbSyn87 without 


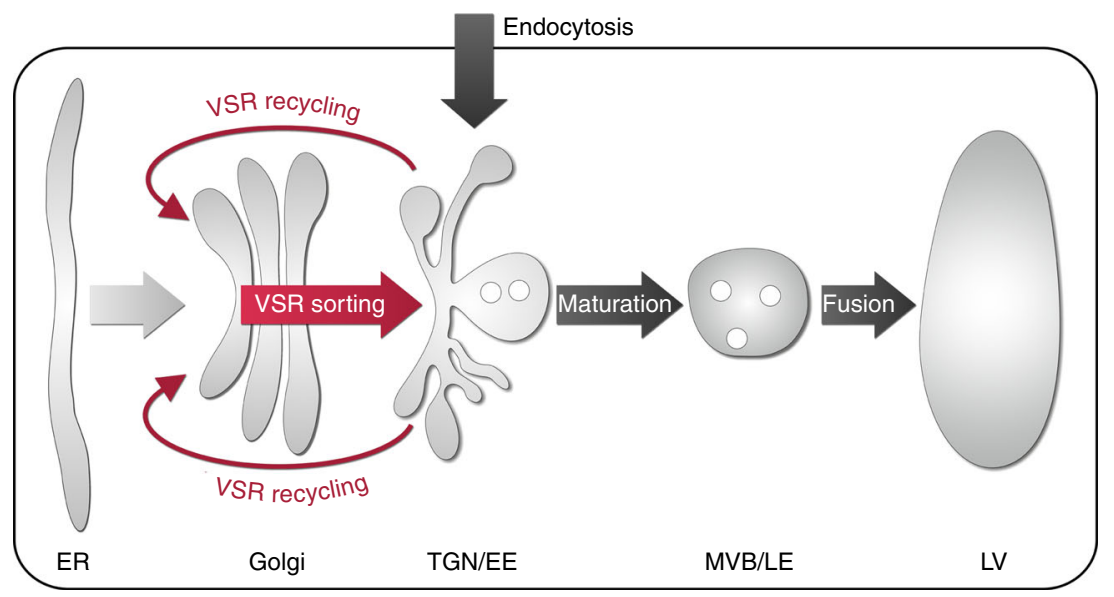

Fig. 6 Model for receptor-mediated vacuolar sorting in plants. VSRs bind ligands in the early secretory pathway and transport them to the TGN/EE. There, the ligands are released from the VSR. Next, VSRs are recycled back to the cis-Golgi stack for further rounds of ligand transport. Post-TGN/EE transport of released vacuolar cargo ligands but also endocytosed proteins occurs independent of VSRs and travel to the lytic vacuole per default. Transport in this route is mediated by multivesicular bodies, the late endosomes (MVBs/LEs). They bud off the TGN/EE in a maturation-based step and confer cargo delivery by their ultimate fusion with the lytic vacuole (LV)

the C-terminal 6xHis tag ${ }^{32}$, optimized for Arabidopsis-specific codon usage (EMBOSS Backtranseq), modified with an N-terminal HA-tag and chemically synthesized (GeneArt Gene Synthesis). The blue fluorescent protein mTagBFP2 (GenBank AIQ82697.1) was also generated by reverse translation of the amino acid sequence, optimized for Arabidopsis-specific codon usage (EMBOSS Backtranseq) and chemically synthesized (GeneArt Gene Synthesis).

All VSR constructs were assembled from AtVSR4 (GenBank accession no. NM_127036) and fused to the GFP nanobody ${ }^{27}$. The red fluorescent compartmentspecific anchors carry a monomeric RFP ${ }^{48}$. The correct localization of all generated VSR-/marker-fluorophore fusions was verified.

Protoplast isolation and gene expression. Protoplasts were isolated from perforated leafs by overnight incubation in incubation buffer $\left(3.05 \mathrm{~g} \mathrm{~L}^{-1}\right.$ Gamborg B5 Medium, $500 \mathrm{mg} \mathrm{L}^{-1} \mathrm{MES}, 750 \mathrm{mg} \mathrm{L}^{-1} \mathrm{CaCl}_{2} \cdot 2 \mathrm{H}_{2} \mathrm{O}, 250 \mathrm{mg} \mathrm{L}^{-1} \mathrm{NH}_{4} \mathrm{NO}_{3}$ adjusted to $\mathrm{pH} 5.7$ with $\mathrm{KOH}$ ) supplemented with $0.2 \% \mathrm{w} / \mathrm{v}$ macerozyme and $0.4 \% \mathrm{w} / \mathrm{v}$ cellulase) at $25^{\circ} \mathrm{C}$ in the dark. They were rebuffered by washing them three times in $50 \mathrm{~mL}$ electrotransfection-buffer $\left(137 \mathrm{~g} \mathrm{~L}^{-1}\right.$ sucrose, $2.4 \mathrm{~g} \mathrm{~L}^{-1}$ HEPES, $6 \mathrm{~g} \mathrm{~L}^{-1} \mathrm{KCl}, 600 \mathrm{mg} \mathrm{L}^{-1} \mathrm{CaCl}_{2} \cdot 2 \mathrm{H}_{2} \mathrm{O}$ adjusted to $\mathrm{pH} 7.2$ with $\mathrm{KOH}$ ). $150 \mu \mathrm{L}$ protoplasts in a total volume of $600 \mu \mathrm{L}$ electrotransfection-buffer were electrotransfected with $1-10 \mu \mathrm{g}$ plasmid DNA using the square-wave pulse generator EPI-2500 (Fischer) applying a pulse at $130 \mathrm{~V}$ for $10 \mathrm{~ms}$. After transfection, each sample was supplemented with $2 \mathrm{ml}$ incubation buffer and incubated for $18-24 \mathrm{~h}$ at $25^{\circ} \mathrm{C}$ in the dark.

Biosynthesis of fluorescent reporters. Protoplast-secreted reporters (GFP/ GFP-SYN) for endocytic uptake experiments were obtained from cell-free culture medium after expression, harvesting, sonication and clearance, ruling out contaminations with reporter-synthesizing cells during uptake experiments. For the endocytic uptake, populations of protoplasts expressing $\mathrm{Nb}_{\mathrm{G}} / \mathrm{Nb}_{\mathrm{S}}$-tagged constructs were supplemented with cleared reporter-containing medium for $20 \mathrm{~h}$.

Confocal microscopy and statistical analysis. Image acquisition was performed using a Leica TCS-SP8 confocal laser-scanning microscope, equipped with a $\times 63$ (1.2 numerical aperture) water immersion objective. Fluorophores were excited (ex) and emission (em) was detected in sequential line scanning mode using HyD detectors: mTagBFP2 (ex/em, $405 \mathrm{~nm} / 407-452 \mathrm{~nm}$ ), GFP (ex/em, $488 \mathrm{~nm} /$ 496-525 nm) and RFP (ex/em, $561 \mathrm{~nm} / 569-636 \mathrm{~nm}$ ). Pinholes were adjusted to 1 Airy unit for each wavelength. Post-acquisition image processing and assembly of figures was performed using Adobe Photoshop CS3 and CorelDraw $\mathrm{X} 8$.

The linear Pearson's correlation coefficient $\left(r_{\mathrm{P}}\right)$ and the nonlinear Spearman's rank coefficient $\left(r_{\mathrm{S}}\right)$ of green and red fluorescent signals was calculated with the PSC colocalization plug-in (http://www.cpib.ac.uk/ afrench/coloc.html) for Image ${ }^{48}$. The threshold levels were set to 10 . For the statistics, 10 individual cells were analyzed and the correlation coefficients are shown as mean values with standard errors of the mean. Statistical significance was calculated with $\mathrm{R}$ using an unpaired, two tailed $t$-test ${ }^{49}$.
Analysis of the SYN nanobody-epitope interaction. Cell-free culture medium was harvested after flotation of electrotransfected tobacco protoplasts for $5 \mathrm{~min}$ at $80 \mathrm{~g}$ in sealed pre-punctured tubes, using insulin syringes. Afterwards, cells were harvested by addition of $7.5 \mathrm{~mL}$ of $250 \mathrm{mM} \mathrm{NaCl}$, sedimentation for $7 \mathrm{~min}$ at $80 \mathrm{~g}$, followed by removal of the supernatant. The culture medium was cleared by centrifugation at $20,000 \times g$ for $15 \mathrm{~min}$ at $4{ }^{\circ} \mathrm{C}$ and diluted with $\alpha$-amylase extraction buffer ( $50 \mathrm{mM}$ acid malic, $50 \mathrm{mM}$ sodium chloride, $2 \mathrm{mM}$ calcium chloride, $0.02 \%$ $(\mathrm{w} / \mathrm{v})$ sodium azide). Cell samples were extracted in a total volume of $250 \mu \mathrm{g}$ with $\alpha$-amylase extraction buffer, sonicated and centrifuged at $20,000 \mathrm{~g}$ for $15 \mathrm{~min}$ at $4^{\circ}$ $\mathrm{C}$. The supernatant was recovered and employed for the reporter assay and SDS-PAGE/western blot (SDS-PAGE/WB).

The quantitative reporter transport analysis was performed in samples from the cell extracts and the culture medium, using the $\alpha$-amylase reagent kit (Megazyme R-CAAR4). Individual enzymatic assays were started by addition of $30 \mu \mathrm{l}$ of substrate solution to $30 \mu \mathrm{l}$ of extracted and diluted sample. After incubation at $40^{\circ}$ $\mathrm{C}$, the reaction was stopped by the addition of $150 \mu \mathrm{L}$ of $1 \% \mathrm{w} / \mathrm{v}$ Trizma base. 200 $\mu \mathrm{L}$ of the reaction was transferred into a well of a microtitre plate to measure absorbance at $405 \mathrm{~nm}^{50}$.

For SDS-PAGE/WB, samples were mixed 1:1 with freshly prepared $2 \times$ Xtreme loading dye $(900 \mu \mathrm{L}$ of sample buffer $(0.1 \%(\mathrm{w} / \mathrm{v})$ bromophenol blue, $5 \mathrm{mM}$ EDTA, $200 \mathrm{mM}$ Tris- $\mathrm{HCl}, \mathrm{pH} 8.8,1 \mathrm{M}$ sucrose) supplemented with $300 \mu \mathrm{L} 10 \% \mathrm{w} / \mathrm{v}$ SDS and $20 \mu \mathrm{L}$ of $1 \mathrm{M} \mathrm{DTT}$ ), incubated for $5 \mathrm{~min}$ at $95^{\circ} \mathrm{C}$ and loaded onto $10 \%(\mathrm{w} / \mathrm{v})$ SDS-polyacrylamide gels. After electrophoretic separation at $40 \mathrm{~mA}$, proteins were electroblotted onto nitrocellulose membranes at $200 \mathrm{~mA}$. For immunodetection, membranes were incubated in blocking solution (TBS-T $\left(6.06 \mathrm{~g} \mathrm{~L}^{-1}\right.$ Trizma base, $8.88 \mathrm{~g} \mathrm{~L}^{-1} \mathrm{NaCl}, 0.05 \%(\mathrm{v} / \mathrm{v})$ Tween-20), supplemented with $\left.5 \%(\mathrm{w} / \mathrm{v}) \mathrm{BSA}\right)$ for $30 \mathrm{~min}$ and then probed with the following antibodies diluted in blocking solution: rabbit polyclonal anti-GFP (Life Technologies A6455, 1:10,000), rat monoclonal anti-RFP (ChromoTek 5F8, 1:1000) and rat monoclonal anti-HA-Peroxidase (Roche 12013819001, 1:2500). Uncropped immunoblots are given in Supplementary Fig. 7.

Immunoprecipitation. For anchor-epitope and VSR-epitope interaction anchors/ VSRs were expressed in vivo and extracted 1:1 in $2 \times$ binding buffer $(40 \mathrm{mM}$ HEPES, $300 \mathrm{mM} \mathrm{NaCl}, 2 \mathrm{mM} \mathrm{CaCl}_{2}, 2 \mathrm{mM} \mathrm{MgCl}_{2}$, pH 7.1) with $2 \%$ (v/v) CHAPS $^{27}$. Immunoprecipitation was performed for $1 \mathrm{~h}$ with RFP-Trap_MA (ChromoTek, rxns-20) for the anchors and with Pierce Anti-HA Magnetic Beads (Life Technologies, 88836) for the VSRs at $4^{\circ} \mathrm{C}$. Beads were washed three times with binding buffer containing $0.4 \%(\mathrm{v} / \mathrm{v})$ CHAPS and afterwards incubated with GFP-SYN/GFP, which were in parallel samples transiently expressed and recovered from the medium, overnight at $4{ }^{\circ} \mathrm{C}$. SDS-PAGE/WB was performed as described above.

Data availability. The authors declare that all data supporting the findings of this study are available within the manuscript and its supplementary files or are available from the corresponding author upon request.

Received: 15 April 2017 Accepted: 8 January 2018

Published online: 13 February 2018 


\section{References}

1. Paez Valencia, J., Goodman, K. \& Otegui, M. S. Endocytosis and endosomal trafficking in plants. Annu. Rev. Plant. Biol. 67, 309-335 (2016).

2. Carmona-Gutierrez, D., Hughes, A. L., Madeo, F. \& Ruckenstuhl, C. The crucial impact of lysosomes in aging and longevity. Ageing Res. Rev. 32, 2-12 (2016).

3. Jackson, M. P. \& Hewitt, E. W. Cellular proteostasis: degradation of misfolded proteins by lysosomes. Essays Biochem. 60, 173-180 (2016).

4. Schroder, B. \& Saftig, P. Intramembrane proteolysis within lysosomes. Ageing Res. Rev. 32, 51-64 (2016).

5. Robinson, D. G. \& Neuhaus, J. M. Receptor-mediated sorting of soluble vacuolar proteins: myths, facts, and a new model. J. Exp. Bot. 67, 4435-4449 (2016).

6. Robinson, D. G. \& Pimpl, P. Receptor-mediated transport of vacuolar proteins: a critical analysis and a new model. Protoplasma 251, 247-264 (2014)

7. Goldstein, J. L. \& Brown, M. S. Binding and degradation of low density lipoproteins by cultured human fibroblasts. Comparison of cells from a normal subject and from a patient with homozygous familial hypercholesterolemia. J. Biol. Chem. 249, 5153-5162 (1974).

8. Gonzalez-Noriega, A., Grubb, J. H., Talkad, V. \& Sly, W. S. Chloroquine inhibits lysosomal enzyme pinocytosis and enhances lysosomal enzyme secretion by impairing receptor recycling. J. Cell. Biol. 85, 839-852 (1980).

9. Hoflack, B. \& Kornfeld, S. Purification and characterization of a cation dependent mannose 6-phosphate receptor from murine P388D1 macrophages and bovine liver. J. Biol. Chem. 260, 12008-12014 (1985).

10. Mellman, I., Fuchs, R. \& Helenius, A. Acidification of the endocytic and exocytic pathways. Annu. Rev. Biochem. 55, 663-700 (1986).

11. Rome, L. H., Weissmann, B. \& Neufeld, E. F. Direct demonstration of binding of a lysosomal enzyme, alpha-L-iduronidase, to receptors on cultured fibroblasts. Proc. Natl Acad. Sci. USA 76, 2331-2334 (1979).

12. Sahagian, G. G. \& Neufeld, E. F. Biosynthesis and turnover of the mannose 6phosphate receptor in cultured Chinese hamster ovary cells. J. Biol. Chem. 258, 7121-7128 (1983)

13. Brown, M. S., Anderson, R. G., Basu, S. K. \& Goldstein, J. L. Recycling of cellsurface receptors: observations from the LDL receptor system. Cold Spring Harb. Symp. Quant. Biol. 46, 713-721 (1982).

14. Duncan, J. R. \& Kornfeld, S. Intracellular movement of two mannose 6phosphate receptors: return to the Golgi apparatus. J. Cell. Biol. 106, 617-628 (1988).

15. Ahmed, S. U., Bar-Peled, M. \& Raikhel, N. V. Cloning and subcellular location of an Arabidopsis receptor-like protein that shares common features with protein-sorting receptors of eukaryotic cells. Plant. Physiol. 114, 325-336 (1997).

16. Paris, N. et al. Molecular cloning and further characterization of a probable plant vacuolar sorting receptor. Plant Physiol. 115, 29-39 (1997).

17. Cao, X., Rogers, S. W., Butler, J., Beevers, L. \& Rogers, J. C. Structural requirements for ligand binding by a probable plant vacuolar sorting receptor. Plant Cell 12, 493-506 (2000).

18. Luo, F. et al. How vacuolar sorting receptor proteins interact with their cargo proteins: crystal structures of apo and cargo-bound forms of the proteaseassociated domain from an Arabidopsis vacuolar sorting receptor. Plant Cell 26, 3693-3708 (2014).

19. daSilva, L. L., Foresti, O. \& Denecke, J. Targeting of the plant vacuolar sorting receptor BP80 is dependent on multiple sorting signals in the cytosolic tail. Plant Cell 18, 1477-1497 (2006).

20. Happel, N. et al. Arabidopsis micro A-adaptin interacts with the tyrosine motif of the vacuolar sorting receptor VSR-PS1. Plant J. 37, 678-693 (2004)

21. Kirsch, T., Paris, N., Butler, J. M., Beevers, L. \& Rogers, J. C. Purification and initial characterization of a potential plant vacuolar targeting receptor. Proc. Natl Acad. Sci. USA 91, 3403-3407 (1994)

22. Shen, J., Ding, Y., Gao, C., Rojo, E. \& Jiang, L. N-linked glycosylation of AtVSR1 is important for vacuolar protein sorting in Arabidopsis. Plant J. 80, 977-992 (2014).

23. Watanabe, E. et al. An ER-localized form of PV72, a seed-specific vacuolar sorting receptor, interferes the transport of an NPIR-containing proteinase in Arabidopsis leaves. Plant Cell Physiol. 45, 9-17 (2004).

24. $\mathrm{Li}, \mathrm{Y}$. B. et al. BP-80 and homologs are concentrated on post-Golgi, probable lytic prevacuolar compartments. Plant Cell Physiol. 43, 726-742 (2002).

25. Tse, Y. C. et al. Identification of multivesicular bodies as prevacuolar compartments in Nicotiana tabacum BY-2 cells. Plant Cell 16, 672-693 (2004).

26. Martiniere, A. et al. In vivo intracellular $\mathrm{pH}$ measurements in tobacco and Arabidopsis reveal an unexpected $\mathrm{pH}$ gradient in the endomembrane system. Plant Cell 25, 4028-4043 (2013).
27. Künzl, F., Früholz, S., Fäßler, F., Li, B. \& Pimpl, P. Receptor-mediated sorting of soluble vacuolar proteins ends at the trans-Golgi network/early endosome. Nat. Plants 2, 16017 (2016).

28. Dettmer, J., Hong-Hermesdorf, A., Stierhof, Y. D. \& Schumacher, K. Vacuolar $\mathrm{H}+$-ATPase activity is required for endocytic and secretory trafficking in Arabidopsis. Plant Cell 18, 715-730 (2006).

29. Lam, S. K. et al. Rice SCAMP1 defines clathrin-coated, trans-Golgi-located tubular-vesicular structures as an early endosome in tobacco BY-2 cells. Plant Cell 19, 296-319 (2007).

30. Rothbauer, U. et al. Targeting and tracing antigens in live cells with fluorescent nanobodies. Nat. Methods 3, 887-889 (2006).

31. Kubala, M. H., Kovtun, O., Alexandrov, K. \& Collins, B. M. Structural and thermodynamic analysis of the GFP:GFP-nanobody complex. Protein Sci. 19, 2389-2401 (2010)

32. Guilliams, T. et al. Nanobodies raised against monomeric alpha-synuclein distinguish between fibrils at different maturation stages. J. Mol. Biol. 425, 2397-2411 (2013).

33. Saint-Jean, B., Seveno-Carpentier, E., Alcon, C., Neuhaus, J. M. \& Paris, N. The cytosolic tail dipeptide Ile-Met of the pea receptor BP80 is required for recycling from the prevacuole and for endocytosis. Plant Cell 22, 2825-2837 (2010).

34. Shen, Y. et al. The rice RMR1 associates with a distinct prevacuolar compartment for the protein storage vacuole pathway. Mol. Plant 4, 854-868 (2011).

35. Niemes, S. et al. Retromer recycles vacuolar sorting receptors from the transGolgi network. Plant J. 61, 107-121 (2010).

36. Rogers, J. C. Two barley alpha-amylase gene families are regulated differently in aleurone cells. J. Biol. Chem. 260, 3731-3738 (1985).

37. Ritzenthaler, C. et al. Reevaluation of the effects of brefeldin A on plant cells using tobacco Bright Yellow 2 cells expressing Golgi-targeted green fluorescent protein and COPI antisera. Plant Cell 14, 237-261 (2002).

38. Hamers-Casterman, C. et al. Naturally occurring antibodies devoid of light chains. Nature 363, 446-448 (1993).

39. Steeland, S., Vandenbroucke, R. E. \& Libert, C. Nanobodies as therapeutics: big opportunities for small antibodies. Drug Discov. Today 21, 1076-1113 (2016).

40. Dmitriev, O. Y., Lutsenko, S. \& Muyldermans, S. Nanobodies as probes for protein dynamics in vitro and in cells. J. Biol. Chem. 291, 3767-3775 (2016).

41. Niemes, S. et al. Sorting of plant vacuolar proteins is initiated in the ER. Plant J. 62, 601-614 (2010).

42. Gershlick, D. C. et al. Golgi-dependent transport of vacuolar sorting receptors is regulated by COPII, AP1, and AP4 protein complexes in tobacco. Plant Cell 26, 1308-1329 (2014)

43. Shen, J. et al. Organelle $\mathrm{pH}$ in the Arabidopsis endomembrane system. Mol. Plant 6, 1419-1437 (2013).

44. Luo, Y. et al. V-ATPase activity in the TGN/EE is required for exocytosis and recycling in Arabidopsis. Nat. Plants 1, 15094 (2015).

45. Viotti, C. et al. The endoplasmic reticulum is the main membrane source for biogenesis of the lytic vacuole in Arabidopsis. Plant Cell 25, 3434-3449 (2013).

46. Scheuring, D. et al. Multivesicular bodies mature from the trans-Golgi network/early endosome in Arabidopsis. Plant Cell 23, 3463-3481 (2011).

47. Singh, M. K. et al. Protein delivery to vacuole requires SAND proteindependent Rab GTPase conversion for MVB-vacuole fusion. Curr. Biol. 24, 1383-1389 (2014)

48. Scheuring, D. et al. Ubiquitin initiates sorting of Golgi and plasma membrane proteins into the vacuolar degradation pathway. BMC Plant Biol. 12, 164 (2012).

49. R. Core Team. R: A language and environment for statistical computing. $\mathrm{R}$ Foundation for Statistical Computing, Vienna, Austria (2016).

50. Foresti, O., daSilva, L. L. \& Denecke, J. Overexpression of the Arabidopsis syntaxin PEP12/SYP21 inhibits transport from the prevacuolar compartment to the lytic vacuole in vivo. Plant Cell 18, 2275-2293 (2006).

\section{Acknowledgements}

We thank Diana Vranjkovic for technical help. The financial support of the Deutsche Forschungsgemeinschaft (PI 769/1-2 and the Collaborative Research Centre SFB 1101 "Molecular Encoding of Specificity in Plant Processes" and TP A03) and the Deutscher Akademischer Austauschdienst (Project 57057314 \& 57219822) and the Southern University of Science and Technology (SUSTech)/SUSTech-PKU Institute of Plant and Food Science (IPFS) Start-up fund is gratefully acknowledged. P.P. is indebted to L. Kilmister for inspirations and support. 


\section{Author contributions}

S.F., F.F., Ü.K., and P.P. designed and analyzed experiments. S.F. performed experiments. S.F. and P.P. wrote the manuscript, P.P. conceived the study.

\section{Additional information}

Supplementary Information accompanies this paper at https://doi.org/10.1038/s41467018-02909-6.

Competing interests: The authors declare no competing financial interests.

Reprints and permission information is available online at http://npg.nature.com/ reprintsandpermissions/

Publisher's note: Springer Nature remains neutral with regard to jurisdictional claims in published maps and institutional affiliations. (c) (i) Open Access This article is licensed under a Creative Commons Attribution 4.0 International License, which permits use, sharing, adaptation, distribution and reproduction in any medium or format, as long as you give appropriate credit to the original author(s) and the source, provide a link to the Creative Commons license, and indicate if changes were made. The images or other third party material in this article are included in the article's Creative Commons license, unless indicated otherwise in a credit line to the material. If material is not included in the article's Creative Commons license and your intended use is not permitted by statutory regulation or exceeds the permitted use, you will need to obtain permission directly from the copyright holder. To view a copy of this license, visit http://creativecommons.org/ licenses/by/4.0/.

(C) The Author(s) 2018 